\title{
Contemporary rates and predictors of fast progression of chronic kidney disease in adults with and without diabetes mellitus
}

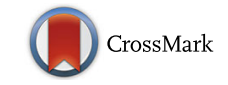

\author{
Alan S. Go ${ }^{1,2,3^{*}}$ D, Jingrong Yang ${ }^{1}$, Thida C. Tan ${ }^{1}$, Claudia S. Cabrera ${ }^{4}$, Bergur V. Stefansson ${ }^{4}$, Peter J. Greasley ${ }^{4}$, \\ Juan D. Ordonez ${ }^{5}$ and for the Kaiser Permanente Northern California CKD Outcomes Study
}

\begin{abstract}
Background: Chronic kidney disease (CKD) is highly prevalent but identification of patients at high risk for fast CKD progression before reaching end-stage renal disease in the short-term has been challenging. Whether factors associated with fast progression vary by diabetes status is also not well understood. We examined a large community-based cohort of adults with CKD to identify predictors of fast progression during the first 2 years of follow-up in the presence or absence of diabetes mellitus.

Methods: Within a large integrated healthcare delivery system in northern California, we identified adults with estimated glomerular filtration rate (eGFR) 30-59 ml/min/1.73 $\mathrm{m}^{2}$ by CKD-EPI equation between 2008 and 2010 who had no previous dialysis or renal transplant, who had outpatient serum creatinine values spaced 10-14 months apart and who did not initiate renal replacement therapy, die or disenroll during the first 2 years of follow-up. Through 2012, we calculated the annual rate of change in eGFR and classified patients as fast progressors if they lost $>4 \mathrm{ml} / \mathrm{min} / 1$. $73 \mathrm{~m}^{2}$ per year. We used multivariable logistic regression to identify patient characteristics that were independently associated with fast CKD progression stratified by diabetes status.

Results: We identified 36,195 eligible adults with eGFR 30-59 ml/min/1.73 $\mathrm{m}^{2}$ and mean age 73 years, 55\% women, $11 \%$ black, $12 \%$ Asian/Pacific Islander and 36\% with diabetes mellitus. During 24-month follow-up, fast progression of CKD occurred in $23.0 \%$ of patients with diabetes vs. $15.3 \%$ of patients without diabetes. Multivariable predictors of fast CKD progression that were similar by diabetes status included proteinuria, age $\geq 80$ years, heart failure, anemia and higher systolic blood pressure. Age 70-79 years, prior ischemic stroke, current or former smoking and lower HDL cholesterol level were also predictive in patients without diabetes, while age 18-49 years was additionally predictive in those with diabetes.

Conclusions: In a large, contemporary population of adults with eGFR 30-59 ml/min/1.73 m², accelerated progression of kidney dysfunction within 2 years affected $\sim 1$ in 4 patients with diabetes and $\sim 1$ in 7 without diabetes. Regardless of diabetes status, the strongest independent predictors of fast CKD progression included proteinuria, elevated systolic blood pressure, heart failure and anemia.
\end{abstract}

Keywords: Diabetes, Chronic kidney disease, Progression, Risk factors, Proteinuria, Anemia, Blood pressure

\footnotetext{
* Correspondence: Alan.S.Go@kp.org

${ }^{1}$ Division of Research, Kaiser Permanente Northern California, 2000 Broadway,

Oakland, CA, USA

${ }^{2}$ Departments of Epidemiology, Biostatistics and Medicine, University of

California, San Francisco, San Francisco, CA, USA

Full list of author information is available at the end of the article
}

(c) The Author(s). 2018 Open Access This article is distributed under the terms of the Creative Commons Attribution 4.0 International License (http://creativecommons.org/licenses/by/4.0/), which permits unrestricted use, distribution, and reproduction in any medium, provided you give appropriate credit to the original author(s) and the source, provide a link to the Creative Commons license, and indicate if changes were made. The Creative Commons Public Domain Dedication waiver (http://creativecommons.org/publicdomain/zero/1.0/) applies to the data made available in this article, unless otherwise stated. 


\section{Background}

The population burden of chronic kidney disease (CKD) is high, with an estimated prevalence of $15 \%$ of U.S. adults in $2007-2012$ [1] and $3.3-17.3 \%$ in 13 European populations [2]. CKD is independently associated with excess cardiovascular events, death, hospitalization and other adverse outcomes [3]. Stage 3 CKD, defined as an eGFR 30 to $59 \mathrm{ml} / \mathrm{min} / 1.73 \mathrm{~m}^{2}$, makes up the largest fraction of CKD patients [1] and carries the highest potential to intervene early and affect the natural history of the disease.

Despite being relatively common, only a small fraction of patients with eGFR 30 to $59 \mathrm{ml} / \mathrm{min} / 1.73 \mathrm{~m}^{2}$ progress to end-stage renal disease (ESRD) over their lifetime, with diabetes mellitus being one of the commonly attributed factors [4]. Previous research has focused primarily on the outcome of receipt of renal replacement therapy (chronic dialysis or receipt of renal transplant) that occurs often many years in the future [5-8] and is subject to important biases given that the definition of ESRD is currently based on receiving a procedure [9]. More rapid progression of CKD is associated with worse clinical outcomes (e.g., cardiovascular events and death) independent of current level of eGFR [10-14]. However, predicting which subset of patients are at high risk for progression of their CKD in the short-term is challenging but more clinically and policy relevant when prioritizing resources targeting the highest risk patients to potentially avoid or significantly delay the need for renal replacement therapy and potentially preventing cardiovascular and other adverse outcomes [15]. Prior research on fast progression of CKD has been limited by modest-sized samples, under-representation of racial/ethnic minorities, or being conducted during older eras not reflecting contemporary therapy and management [16-20]. Relatively little is known about whether predictors of the fast CKD progression of CKD varies by diabetes mellitus status, and this could have further clinical and population management implications.

Within a large, diverse cohort of adults with mild-to-moderate CKD, we evaluated contemporary two-year rates and predictors of fast progression of CKD. We hypothesized that there would be higher rates of fast progression in the presence of diabetes and that risk factors may differ based on the presence or absence of diabetes.

\section{Methods}

\section{Source population}

The study was based in KPNC, a large integrated healthcare delivery system currently providing comprehensive care to $>4.4$ million members in the San Francisco and greater Bay Area. The KPNC membership is highly representative of the surrounding local and statewide population [21].

\section{Cohort assembly}

We identified all adult ( $\geq 18$ years old) health plan members between January 1, 2008 and December 31, 2010 who had at least one ambulatory, non-emergency department serum creatinine measurement within a regional health plan laboratory and estimated glomerular filtration rate (eGFR) using the CKD-EPI equation [22]. Index date was defined using the first identified serum creatinine measurement during the inception period. We excluded patients whose index eGFR was not between the range of 30 and $59 \mathrm{ml} / \mathrm{min} / 1.72 \mathrm{~m}^{2}$. In addition, we excluded patients who had less than 12 months of continuous health plan membership and pharmacy benefit before the index date (defined as the date of the first eGFR test during the inception period) to ensure adequate baseline information. We also excluded those who died, disenrolled or initiated renal replacement therapy (chronic dialysis or receipt of renal transplant) within 24 months after the index date. Deaths were identified from health plan administrative databases (including member proxy reporting), Social Security Administrative vital status files [23], and California state death certificate files [24]. Health plan disenrollment was defined as a continuous membership gap of $>30$ days. We also excluded patients without outpatient, non-emergency department eGFR values spaced 10-14 months apart in order to approximate annual measurements during 2 years of follow-up.

\section{Follow-up and definition of fast progression of CKD}

Follow-up occurred through December 31, 2012 for occurrence of CKD progression in eligible patients. We searched only for outpatient, non-emergency department measurements of eGFR for each patient during the first 24 months of follow-up, during which the median number of eGFR measurements was 4 (interquartile range: 3 to 7 ). We then calculated the annual rate of change in eGFR by fitting a linear regression model where the dependent variable was eGFR consisting of only their baseline and the subsequent two outpatient, non-emergency eGFR values spaced 1014 months apart during follow-up to ensure consistency across all patients. Fast progression of CKD was defined as experiencing a loss of eGFR $>4 \mathrm{ml} / \mathrm{min} / 1.73 \mathrm{~m}^{2}$ per year [25].

\section{Baseline covariates}

Patient demographic characteristics (age, gender and self-reported race/ethnicity) were ascertained from health plan databases. Comorbid conditions were defined based on previously described validated algorithms using relevant information from hospitalization, outpatient and emergency department diagnosis and procedure codes; ambulatory pharmacy dispensing; and laboratory databases $[3,26,27]$. A list of specific definitions, codes and data sources are available on request. 
Conditions included myocardial infarction, heart failure, valvular heart disease, coronary revascularization (coronary artery bypass surgery, percutaneous coronary intervention), pacemaker placement, atrial fibrillation and/or flutter, ischemic stroke, transient ischemic attack, peripheral artery disease, cardiovascular risk factors (tobacco usage, diabetes mellitus, hypertension, dyslipidemia), other comorbid conditions (cancer, chronic liver disease, chronic lung disease, dementia, depression, extracranial hemorrhage, thyroid disease). We also ascertained data on ambulatory systolic and diastolic blood pressure, heart rate and body mass index, documented proteinuria based on measures of urine dipstick of $1+$ or greater [3], as well as the most recent ambulatory level of hemoglobin, LDL cholesterol, HDL cholesterol and serum potassium.

\section{Statistical approach}

All analyses were conducted using SAS statistical software, version 9.3 (Cary, N.C.). Continuous variables were reported as means with standard deviations or medians with interquartile ranges; discrete variables were reported as frequencies and proportions. Given the large sample size, we calculated the difference between the means or proportions of the fast progressors versus non-fast progressors divided by the pooled estimate of the standard deviation, to indicate the standardized difference and considered a value of $d \geq 0.10$ to represent a meaningful difference $[28,29]$.

We next calculated the crude risk of fast CKD progression over 24 months by dividing the number of fast progressors by the total number of patients and reported the associated $95 \%$ confidence intervals, stratified by baseline status of diabetes mellitus. To initially identify possible independent predictors of fast CKD progression with or without diabetes mellitus at baseline, we performed a two-step model selection process. First, we performed a multivariable logistic regression model stratified by presence or absence of diabetes including all baseline variables in Table 1 as of study entry date, except for specific laboratory measurements in which $\geq 15 \%$ of the patients had no data for that laboratory measurement, as well as any conditions with $\leq 1 \%$ prevalence at baseline. For self-reported race and eligible laboratory measurements, we included a category for unknown. Second, we included in the final multivariable stratified models patient age, gender, race, Hispanic ethnicity, hemoglobin levels and only the subset of other variables that were significantly associated with fast CKD progression using a cutoff of $P<0.05$ from the initial logistic regression models. Finally, in sensitivity analyses, results were not significantly different if we included the 368 patients who initiated dialysis or received kidney transplantation within the first 2 years of follow-up as fast CKD progressors or if we included or excluded baseline eGFR level, so only results of the main analysis are presented (data not shown).

Using the final models, we also examined model accuracy by evaluating calibration (i.e., how correctly the model predicts absolute risk) as well as discrimination (i.e., the ability of the model to identify higher vs. lower risk patients) to provide insights into the clinical utility of our findings [30].

\section{Results}

\section{Cohort assembly and baseline characteristics}

We identified 36,195 eligible adults with index eGFR 30 to $59 \mathrm{ml} / \mathrm{min} / 1.73 \mathrm{~m}^{2}$ between January 1, 2008 and December 31, 2010, with $36 \%$ of patients having diabetes mellitus. In the overall cohort, mean age was 73.0 years with $55 \%$ being women, $11 \%$ black/African American, $12 \%$ Asian/Pacific Islander and 10\% Hispanic (Table 1). Overall, 85\% had hypertension and three quarters of patients had known dyslipidemia (Table 1).

During 2 years of follow-up, the median annual change in renal function in the overall cohort was 0.04 (interquartile range-2.89 to 3.08 ) $\mathrm{ml} / \mathrm{min} /$ $1.73 \mathrm{~m}^{2}$. A total of 6549 patients (18.1\%) experienced fast decline in kidney function over 24 months, with a higher crude risk in those with vs. without diabetes mellitus (Fig. 1). Fast progressors were more likely to have prior cardiovascular diseases (acute myocardial infarction, coronary artery bypass graft surgery, percutaneous coronary intervention, heart failure, atrial fibrillation/atrial flutter, pacemaker) as well as prior ischemic stroke, transient ischemic attack, peripheral artery disease, proteinuria, diabetes mellitus, hypertension, dementia, dyslipidemia, chronic liver disease, and thyroid disease (Table 1). Patients who experienced fast progression were also more likely to have higher mean systolic blood pressure than those who were not fast progressors. In addition, fast progressors were more likely to be receiving angiotensin II receptor blockers, loop diuretics, $\beta$-blockers, calcium channel blockers, alpha blockers, aldosterone receptor antagonists, isosorbide dinitrate/hydralazine, hydralazine, antiarrhythmic therapy, nitrates, digoxin, statin, other lipid lowering therapies, antiplatelet agents, diabetic therapy and erythropoietin (Table 1).

\section{Multivariable predictors of fast CKD progression by diabetes status}

Given our hypothesis that predictors of being a fast progressor may vary in the presence or absence of diabetes, we performed models stratified by baseline diabetes status.

In patients without diabetes mellitus at entry, multivariable predictors of fast CKD progression included age $\geq$ 70 years, heart failure, prior ischemic stroke, prior 
Table 1 Baseline characteristics of adults with index eGFR 30 to $59 \mathrm{ml} / \mathrm{min} / 1.73 \mathrm{~m}^{2}$ between January 1, 2008 and December 31 , 2012 with annual measurements of kidney function, overall and stratified by those who did or did not experience fast progression of CKD

\begin{tabular}{|c|c|c|c|}
\hline Characteristic & $\begin{array}{l}\text { Not Fast CKD Progression } \\
(N=29,646)\end{array}$ & $\begin{array}{l}\text { Fast CKD Progression } \\
(N=6549)\end{array}$ & D-Value \\
\hline \multicolumn{4}{|l|}{ Age, yr } \\
\hline Mean (SD) & $73.0(10.0)$ & $73.3(10.8)$ & 0.03 \\
\hline Gender, $n(\%)$ & & & 0.00 \\
\hline Women & $16,306(55.0)$ & $3598(54.9)$ & \\
\hline Men & $13,340(45.0)$ & $2951(45.1)$ & \\
\hline \multicolumn{4}{|l|}{ Race/Ethnicity, n (\%) } \\
\hline White/European & $21,651(73.0)$ & $4605(70.3)$ & 0.05 \\
\hline Black/African American & $3185(10.7)$ & $790(12.1)$ & 0.05 \\
\hline Asian/Pacific Islander & 3442 (11.6) & $810(12.4)$ & 0.05 \\
\hline Native American & $90(0.3)$ & $28(0.4)$ & 0.05 \\
\hline Other & $135(0.5)$ & $45(0.7)$ & 0.05 \\
\hline Unknown & $1143(3.9)$ & $271(4.1)$ & 0.05 \\
\hline Known Hispanic ethnicity, $n$ (\%) & $2816(9.5)$ & $754(11.5)$ & 0.07 \\
\hline Smoking status, $n(\%)$ & & & 0.08 \\
\hline Current or former smoker & $13,382(45.1)$ & $3215(49.1)$ & \\
\hline Non-smoker & $16,264(54.9)$ & $3334(50.9)$ & \\
\hline \multicolumn{4}{|l|}{ Cardiovascular history, n (\%) } \\
\hline Acute myocardial infarction & $664(2.2)$ & $222(3.4)$ & 0.26 \\
\hline Heart failure & $2675(9.0)$ & $1001(15.3)$ & 0.36 \\
\hline Hospitalized ischemic stroke & $344(1.2)$ & $105(1.6)$ & 0.20 \\
\hline Transient ischemic attack & $483(1.6)$ & $128(2.0)$ & 0.11 \\
\hline Peripheral artery disease & $333(1.1)$ & $103(1.6)$ & 0.21 \\
\hline Mitral and/or aortic valvular disease & $1973(6.7)$ & $479(7.3)$ & 0.06 \\
\hline Atrial fibrillation and/or flutter & $3086(10.4)$ & $830(12.7)$ & 0.13 \\
\hline \multicolumn{4}{|l|}{ Cardiac procedure history, n (\%) } \\
\hline Coronary artery bypass graft surgery & $422(1.4)$ & $112(1.7)$ & 0.11 \\
\hline Percutaneous coronary intervention & $820(2.8)$ & $233(3.6)$ & 0.16 \\
\hline Pacemaker & $310(1.0)$ & $106(1.6)$ & 0.27 \\
\hline \multicolumn{4}{|l|}{ Medical history, $n$ (\%) } \\
\hline Diabetes mellitus & $10,139(34.2)$ & $3035(46.3)$ & 0.31 \\
\hline Proteinuria & $3032(10.2)$ & $1458(22.3)$ & 0.56 \\
\hline Hypertension & $24,838(83.8)$ & $5772(88.1)$ & 0.22 \\
\hline Diagnosed dementia & $685(2.3)$ & $187(2.9)$ & 0.13 \\
\hline Diagnosed depression & $3899(13.2)$ & $903(13.8)$ & 0.03 \\
\hline Dyslipidemia & $22,157(74.7)$ & $5111(78.0)$ & 0.11 \\
\hline Chronic liver disease & $580(2.0)$ & $156(2.4)$ & 0.12 \\
\hline Chronic lung disease & $6299(21.2)$ & $1546(23.6)$ & 0.08 \\
\hline Hyperthyroidism & $865(2.9)$ & $185(2.8)$ & 0.02 \\
\hline Hypothyroidism & 5555 (18.7) & $1216(18.6)$ & 0.01 \\
\hline Systemic cancer & $2042(6.9)$ & $451(6.9)$ & 0.00 \\
\hline Extracranial hemorrhage & $553(1.9)$ & $157(2.4)$ & 0.16 \\
\hline
\end{tabular}


Table 1 Baseline characteristics of adults with index eGFR 30 to $59 \mathrm{ml} / \mathrm{min} / 1.73 \mathrm{~m}^{2}$ between January 1, 2008 and December 31 , 2012 with annual measurements of kidney function, overall and stratified by those who did or did not experience fast progression of CKD (Continued)

\begin{tabular}{|c|c|c|c|}
\hline Characteristic & $\begin{array}{l}\text { Not Fast CKD Progression } \\
(N=29,646)\end{array}$ & $\begin{array}{l}\text { Fast CKD Progression } \\
(N=6549)\end{array}$ & $D$-Value ${ }^{a}$ \\
\hline Body mass index, $\mathrm{kg} / \mathrm{m}^{2}, n(\%)$ & & & 0.03 \\
\hline$<18.5$ & $247(0.8)$ & $66(1.0)$ & \\
\hline $18.5-24.9$ & $6664(22.5)$ & $1418(21.7)$ & \\
\hline $25.0-29.9$ & $10,290(34.7)$ & $2180(33.3)$ & \\
\hline $30.0-39.9$ & $9038(30.5)$ & 2067 (31.6) & \\
\hline$\geq 40.0$ & $1497(5.0)$ & $448(6.8)$ & \\
\hline Unknown & $1910(6.4)$ & $370(5.6)$ & \\
\hline \multicolumn{4}{|l|}{ Systolic blood pressure, mmHg } \\
\hline Mean (SD) & $129.0(16.5)$ & $132.9(18.7)$ & 0.23 \\
\hline \multicolumn{4}{|l|}{ Diastolic blood pressure, $\mathrm{mmHg}$} \\
\hline Mean (SD) & $70.9(10.4)$ & $71.1(11.1)$ & 0.02 \\
\hline \multicolumn{4}{|l|}{ Baseline medication use, $n$ (\%) } \\
\hline Angiotensin-converting enzyme inhibitor & $13,634(46.0)$ & $3252(49.7)$ & 0.09 \\
\hline Angiotensin II receptor blocker & $4335(14.6)$ & $1216(18.6)$ & 0.17 \\
\hline Diuretic & $17,136(57.8)$ & $3997(61.0)$ & 0.08 \\
\hline Loop & $4470(15.1)$ & $1502(22.9)$ & 0.31 \\
\hline Thiazide & $13,377(45.1)$ & $2739(41.8)$ & 0.08 \\
\hline$\beta$-blocker & $15,256(51.5)$ & $3759(57.4)$ & 0.15 \\
\hline Calcium channel blocker & 7607 (25.7) & $2110(32.2)$ & 0.19 \\
\hline Alpha-blocker & 3927 (13.2) & $1023(15.6)$ & 0.12 \\
\hline Aldosterone receptor antagonist & $691(2.3)$ & $191(2.9)$ & 0.14 \\
\hline Isosorbide dinitrate + hydralazine & $66(0.2)$ & $48(0.7)$ & 0.73 \\
\hline Hydralazine & $903(3.0)$ & $374(5.7)$ & 0.40 \\
\hline Antiarrhythmic & $704(2.4)$ & $189(2.9)$ & 0.12 \\
\hline Nitrate & $1478(5.0)$ & $479(7.3)$ & 0.25 \\
\hline Digoxin & $1072(3.6)$ & $303(4.6)$ & 0.16 \\
\hline Statin & $18,442(62.2)$ & $4342(66.3)$ & 0.11 \\
\hline Other lipid-lowering agent & $1880(6.3)$ & $505(7.7)$ & 0.13 \\
\hline Non-steroidal anti-inflammatory drug & 4028 (13.6) & $803(12.3)$ & 0.07 \\
\hline Antiplatelet agent & $1535(5.2)$ & $422(6.4)$ & 0.14 \\
\hline Diabetic therapy & 7945 (26.8) & $2541(38.8)$ & 0.33 \\
\hline Erythropoietin & $160(0.5)$ & $81(1.2)$ & 0.51 \\
\hline \multicolumn{4}{|l|}{ Baseline laboratory values } \\
\hline CKD-EPI eGFR, ml/min/1.73m² & & & 0.07 \\
\hline $45-59$ & $20,263(68.3)$ & $4675(71.4)$ & \\
\hline $30-44$ & $9383(31.7)$ & $1874(28.6)$ & \\
\hline Hemoglobin, g/dL, n (\%) & & & 0.08 \\
\hline$\geq 13.0$ & $15,328(51.7)$ & $2706(41.3)$ & \\
\hline $12.0-12.9$ & $5160(17.4)$ & $1326(20.2)$ & \\
\hline $11.0-11.9$ & $2656(9.0)$ & $937(14.3)$ & \\
\hline $10.0-10.9$ & $994(3.4)$ & $383(5.8)$ & \\
\hline
\end{tabular}


Table 1 Baseline characteristics of adults with index eGFR 30 to $59 \mathrm{ml} / \mathrm{min} / 1.73 \mathrm{~m}^{2}$ between January 1, 2008 and December 31 , 2012 with annual measurements of kidney function, overall and stratified by those who did or did not experience fast progression of CKD (Continued)

\begin{tabular}{|c|c|c|c|}
\hline Characteristic & $\begin{array}{l}\text { Not Fast CKD Progression } \\
(N=29,646)\end{array}$ & $\begin{array}{l}\text { Fast CKD Progression } \\
(N=6549)\end{array}$ & D-Value ${ }^{a}$ \\
\hline $9.0-9.9$ & $315(1.1)$ & $117(1.8)$ & \\
\hline$<9.0$ & $125(0.4)$ & $42(0.6)$ & \\
\hline Unknown & $5068(17.1)$ & $1038(15.8)$ & \\
\hline \multicolumn{4}{|c|}{ Low density lipoprotein cholesterol, mg/dL } \\
\hline Mean (SD) & $97.4(33.1)$ & $94.0(33.6)$ & 0.10 \\
\hline Median (IQR) & $92.0(75.0-116.0)$ & $88.0(71.0-111.0)$ & \\
\hline Range & $12.0-531.0$ & 19.0-339.0 & \\
\hline Missing, $n(\%)$ & $2997(10.1)$ & $659(10.1)$ & \\
\hline \multicolumn{4}{|c|}{ High density lipoprotein cholesterol, mg/dL } \\
\hline Mean (SD) & $49.7(14.2)$ & $48.3(13.8)$ & 0.10 \\
\hline Median (IQR) & $47.0(40.0-57.0)$ & $46.0(39.0-55.0)$ & \\
\hline Range & $10.0-153.0$ & $4.0-178.0$ & \\
\hline Missing, $n(\%)$ & $3560(12.0)$ & $807(12.3)$ & \\
\hline \multicolumn{4}{|c|}{ Serum potassium, mmol/L } \\
\hline Mean (SD) & $4.5(0.5)$ & $4.5(0.5)$ & 0.03 \\
\hline Median (IQR) & $4.5(4.2-4.8)$ & $4.5(4.2-4.8)$ & \\
\hline Range & $2.1-6.7$ & $2.6-7.3$ & \\
\hline Missing, $n(\%)$ & 2761 (9.3) & 376.7) & \\
\hline
\end{tabular}

${ }^{a}$ Represents the Cohen's D-value, calculated by dividing the difference of the group means by the standard deviation, with a $D$-value $\geq 0.10$ considered a meaningful difference

pacemaker implantation, proteinuria, higher entry level of eGFR, lower hemoglobin levels and HDL cholesterol < $50 \mathrm{mg} / \mathrm{dL}$ (Table 2). There was a graded increased independent risk of fast progression with systolic blood pressure above $120 \mathrm{mmHg}$. Model calibration was outstanding across a range of absolute risk of fast CKD progression over 2 years (Fig. 2a and b), while model discrimination was moderate (c statistic 0.64).

In patients with diabetes mellitus at entry, results were largely similar to that found in non-diabetic patients with regards to heart failure, known proteinuria, higher entry level of eGFR, and the increased risk of fast

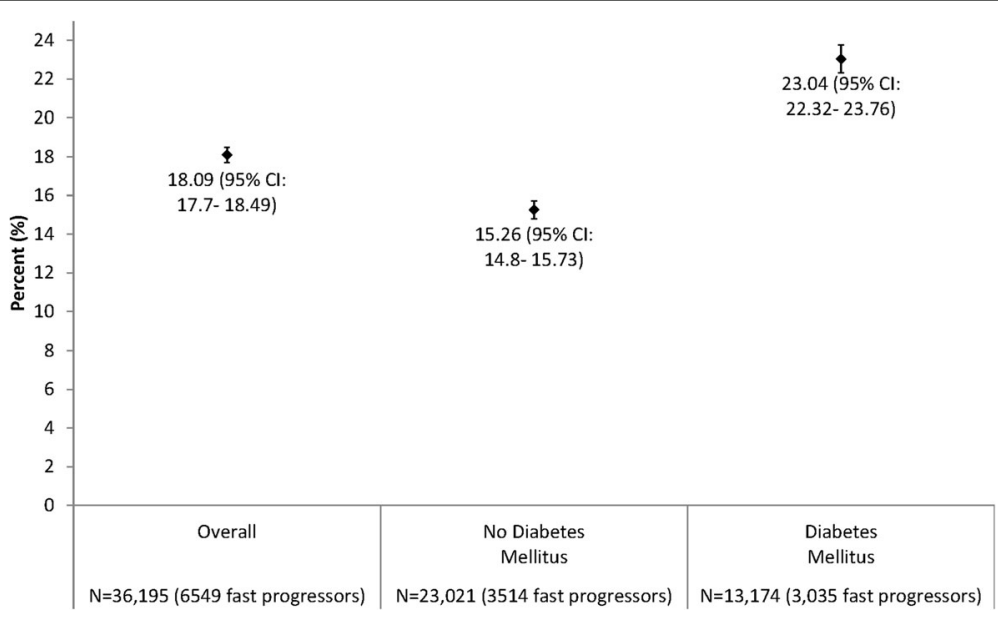

Fig. 1 Risk of fast progression of CKD over 24 months among adults with eGFR 30 to $59 \mathrm{ml} / \mathrm{min} / 1.73 \mathrm{~m}^{2}$, overall and stratified by baseline status of diabetes mellitus 
Table 2 Selected multivariable predictors of fast CKD progression over 24 months among adults with eGFR 30 to $59 \mathrm{ml} / \mathrm{min} /$ $1.73 \mathrm{~m}^{2}$ stratified by baseline diabetes status

\begin{tabular}{|c|c|c|}
\hline Characteristic & $\begin{array}{l}\text { Adjusted }{ }^{a} \text { Odds Ratio }(95 \% \text { Confidence } \\
\text { Interval) for Fast Progression in Adults } \\
\text { with Stage } 3 \text { CKD and no Diabetes } \\
N=23,021\end{array}$ & $\begin{array}{l}\text { Adjusted }{ }^{b} \text { Odds Ratio (95\% Confidence } \\
\text { Interval) for Fast Progression in Adults } \\
\text { with Stage } 3 \text { CKD and Diabetes } \\
N=13,174\end{array}$ \\
\hline \multicolumn{3}{|c|}{ Age group at study entry, yr } \\
\hline $18-49$ & $1.16(0.91-1.48)$ & $1.60(1.22-2.10)$ \\
\hline $50-59$ & $0.72(0.61-0.86)$ & $1.16(1.00-1.34)$ \\
\hline $60-69$ & $0.81(0.73-0.90)$ & $1.03(0.92-1.14)$ \\
\hline $70-79$ & Reference & Reference \\
\hline$\geq 80$ & $1.25(1.14-1.36)$ & $1.16(1.03-1.30)$ \\
\hline Male vs. female gender & $1.00(0.92-1.08)$ & $0.99(0.91-1.08)$ \\
\hline \multicolumn{3}{|l|}{ Race } \\
\hline White/European & Reference & Reference \\
\hline Black/African American & $1.02(0.90-1.16)$ & $1.00(0.88-1.14)$ \\
\hline Asian/Pacific Islander & $1.00(0.88-1.15)$ & $1.02(0.91-1.15)$ \\
\hline Native American & $1.57(0.81-3.04)$ & $1.22(0.67-2.20)$ \\
\hline Other & $1.26(0.68-2.34)$ & $1.24(0.81-1.92)$ \\
\hline Unknown & $0.88(0.69-1.11)$ & $1.15(0.94-1.42)$ \\
\hline Hispanic ethnicity & $1.05(0.90-1.21)$ & $1.03(0.90-1.18)$ \\
\hline Current/former smoking & $1.21(1.12-1.30)$ & - \\
\hline \multicolumn{3}{|l|}{ Medical history } \\
\hline Heart failure & $1.77(1.57-1.99)$ & $1.58(1.40-1.79)$ \\
\hline Ischemic stroke & $1.50(1.11-2.04)$ & - \\
\hline Pacemaker & $1.43(1.06-1.92)$ & - \\
\hline Proteinuria & $1.86(1.65-2.10)$ & $2.31(2.10-2.55)$ \\
\hline Valvular heart disease & - & $0.86(0.71-1.03)$ \\
\hline \multicolumn{3}{|c|}{ Systolic blood pressure, mmHg } \\
\hline$\leq 120$ & Reference & Reference \\
\hline $121-129$ & $1.17(1.04-1.30)$ & $1.14(1.01-1.29)$ \\
\hline $130-139$ & $1.28(1.15-1.41)$ & $1.23(1.08-1.39)$ \\
\hline $140-159$ & $1.44(1.28-1.62)$ & $1.47(1.29-1.68)$ \\
\hline $160-179$ & $2.07(1.75-2.46)$ & $1.99(1.64-2.42)$ \\
\hline$\geq 180$ & $2.42(1.80-3.24)$ & $2.21(1.59-3.08)$ \\
\hline Unknown & $1.12(0.88-1.43)$ & $1.20(0.94-1.53)$ \\
\hline \multicolumn{3}{|l|}{ Laboratory values } \\
\hline \multicolumn{3}{|l|}{ Hemoglobin, g/dL } \\
\hline$\geq 13.0$ & Reference & Reference \\
\hline $12.0-12.9$ & $1.38(1.25-1.53)$ & $1.39(1.23-1.56)$ \\
\hline $11.0-11.9$ & $2.02(1.78-2.29)$ & $1.63(1.43-1.87)$ \\
\hline $10.0-10.9$ & $2.09(1.73-2.54)$ & $1.76(1.47-2.11)$ \\
\hline $9.0-9.9$ & $1.46(1.02-2.10)$ & $2.09(1.55-2.81)$ \\
\hline$<9.0$ & $1.44(0.85-2.43)$ & $2.15(1.26-3.68)$ \\
\hline Unknown & $1.13(1.01-1.26)$ & $1.15(1.02-1.30)$ \\
\hline \multicolumn{3}{|l|}{ HDL cholesterol, mg/dL } \\
\hline$\geq 60$ & Reference & - \\
\hline
\end{tabular}


Table 2 Selected multivariable predictors of fast CKD progression over 24 months among adults with eGFR 30 to $59 \mathrm{ml} / \mathrm{min} /$ $1.73 \mathrm{~m}^{2}$ stratified by baseline diabetes status (Continued)

\begin{tabular}{|c|c|c|}
\hline Characteristic & $\begin{array}{l}\text { Adjusted }{ }^{\text {a }} \text { Odds Ratio (95\% Confidence } \\
\text { Interval) for Fast Progression in Adults } \\
\text { with Stage } 3 \text { CKD and no Diabetes } \\
N=23,021\end{array}$ & $\begin{array}{l}\text { Adjusted }{ }^{\mathrm{b}} \text { Odds Ratio (95\% Confidence } \\
\text { Interval) for Fast Progression in Adults } \\
\text { with Stage } 3 \text { CKD and Diabetes } \\
N=13,174\end{array}$ \\
\hline $50-59$ & $1.09(0.97-1.23)$ & - \\
\hline $40-49$ & $1.16(1.04-1.30)$ & - \\
\hline $35-39$ & $1.25(1.08-1.45)$ & - \\
\hline$<35$ & $1.27(1.07-1.50)$ & - \\
\hline Unknown & $1.20(1.07-1.36)$ & - \\
\hline \multicolumn{3}{|c|}{ LDL cholesterol, mg/dL } \\
\hline$\geq 200$ & - & Reference \\
\hline 160-199 & - & $1.73(1.06-2.84)$ \\
\hline 130-159 & - & $1.07(0.80-1.44)$ \\
\hline $100-129$ & - & $1.10(0.89-1.35)$ \\
\hline 70-99 & - & $1.03(0.90-1.17)$ \\
\hline$<70$ & - & $0.93(0.84-1.02)$ \\
\hline Unknown & - & $1.07(0.82-1.39)$ \\
\hline
\end{tabular}

${ }^{a}$ Adjusted also for baseline level of eGFR and receipt of angiotensin II receptor blockers and calcium channel blockers at entry

${ }^{\mathrm{b}}$ Adjusted also for baseline level of eGFR and receipt of diuretics, calcium channel blockers and hydralazine at entry

progression with lower hemoglobin levels and higher systolic blood pressure, while there was a different association for age in which age 18-49 and $\geq 80$ years were associated with higher adjusted odds of fast progression (Table 2). However, there was no significant multivariable association noted for current or former cigarette smoking, prior ischemic stroke, prior pacemaker implantation or lower HDL cholesterol level (Table 2). Similar to results in patients without diabetes, model calibration was outstanding across an even broader range of absolute risk of fast CKD progression over 2 years (Fig. 3a and b), while model discrimination was moderate (c statistic 0.66).

\section{Discussion}

There has been a growing appreciation that a significant proportion of patients with mild-to-moderate CKD do not progress in a predictable, slow linear pattern, with some patients either not progressing and others having a much faster decline in kidney function [31]. Identifying the subset of mild-to-moderate CKD patients who will subsequently experience fast CKD progression in the short-term has important clinical implications as they may benefit from more intensive monitoring and intervention. To address this, we examined a large, diverse community-based cohort with eGFR 30 to $59 \mathrm{ml} / \mathrm{min} / 1.73 \mathrm{~m}^{2}$ and found that $23 \%$ of these patients with diabetes and $15 \%$ of those without experienced fast CKD progression, and that the significant multivariable factors regardless of diabetes status included age $\geq 80$ years, proteinuria, higher systolic blood pressure, lower hemoglobin level, and known heart failure, even after accounting for initial level of eGFR and receipt of cardiovascular and renal-related medications.

While CKD "progression" has been investigated in various ways, the large majority of studies focused on the end point of ESRD defined as the receipt of chronic dialysis or renal transplantation [5-8]. Other studies have used varying definitions in the absolute or relative amount of drop in eGFR or reaching a particular level of eGFR [32]. While these are all potentially relevant outcomes, existing studies frequently use long time horizons and do not necessarily address the rate of change, which may be more important clinically to identify the subset of patients who are losing kidney function quickly in the short-term and may benefit from earlier, more frequent surveillance and intervention. Toward that end, our cohort of patients with Stage 3 CKD who had annual outpatient measurements of eGFR during 2 years of follow-up provides important insights into the rate of fast CKD progression and associated patient characteristics.

Our finding that documented proteinuria, a reflection of underlying structural kidney damage, is a strong predictor of short-term, fast CKD progression is consistent with other studies that have examined the development of ESRD or significant reductions in the absolute level of eGFR over a longer period of follow-up [5-8, 32].

In patients with diabetes, the youngest patients with CKD were also more likely to experience fast progression after accounting for other potential risk factors and use of cardioprotective and renoprotective therapies, which is consistent with other studies [32] and may reflect a 


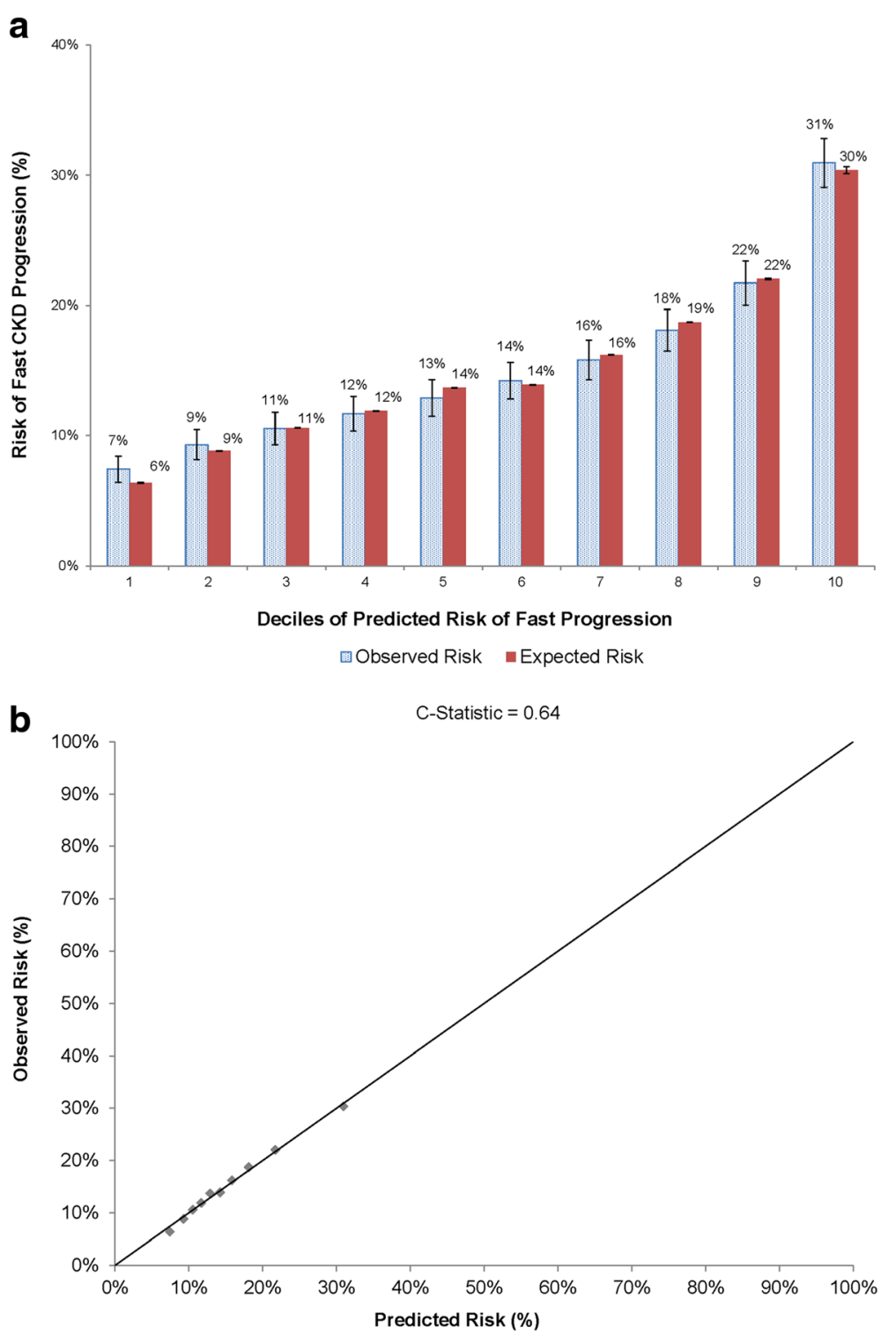

Fig. 2 Accuracy of predictive model for fast CKD progression over 2 years in patients with eGFR 30 to $59 \mathrm{ml} / \mathrm{min} / 1.73 \mathrm{~m}^{2}$ and no diabetes mellitus at entry, based on (a) comparison of observed vs. predicted risks within deciles of predicted risk and (b) model calibration across the spectrum of observed risk

difference in underlying cause(s) of CKD. In contrast, among patients without diabetes, those aged 50-69 years old were less likely than those aged 70-79 years old to have fast CKD progression. Patients $\geq 80$ years were more likely to experience fast progression regardless of diabetes status. We found that current or former cigarette smoking was associated with fast CKD progression in the short-term among patients without diabetes, which is consistent with results from the Cardiovascular Health Study cohort that showed a $31 \%$ relative increase in the likelihood of a serum creatinine increase $\geq 0.3 \mathrm{mg} / \mathrm{dL}$ over 3 years [33]. Furthermore, among 1906 participants in the Italian Longitudinal Study on Aging (ISA) cohort, current smoking $>20$ cigarettes/day was associated with a more than twofold higher odds (adjusted odds ratio 2.29, 95\% CI:1.00-5.27) of an increase in serum creatinine $>0.3 \mathrm{mg} /$ $\mathrm{dL}$ during mean 3.6-year follow-up [34]. However, conflicting results exist about the relationship between smoking history and longer-term endpoints such as the need for renal replacement therapy $[35,36]$.

Higher systolic blood pressure is a well-documented risk factor of development of ESRD [35, 37] or a 50\% reduction in baseline eGFR in patients with CKD [38], but fewer studies have examined the influence of blood pressure on rate of change of eGFR. Among 220 participants with eGFR $30-59 \mathrm{ml} / \mathrm{min} / 1.73 \mathrm{~m}^{2}$ enrolled in the Multi-Ethnic Study 


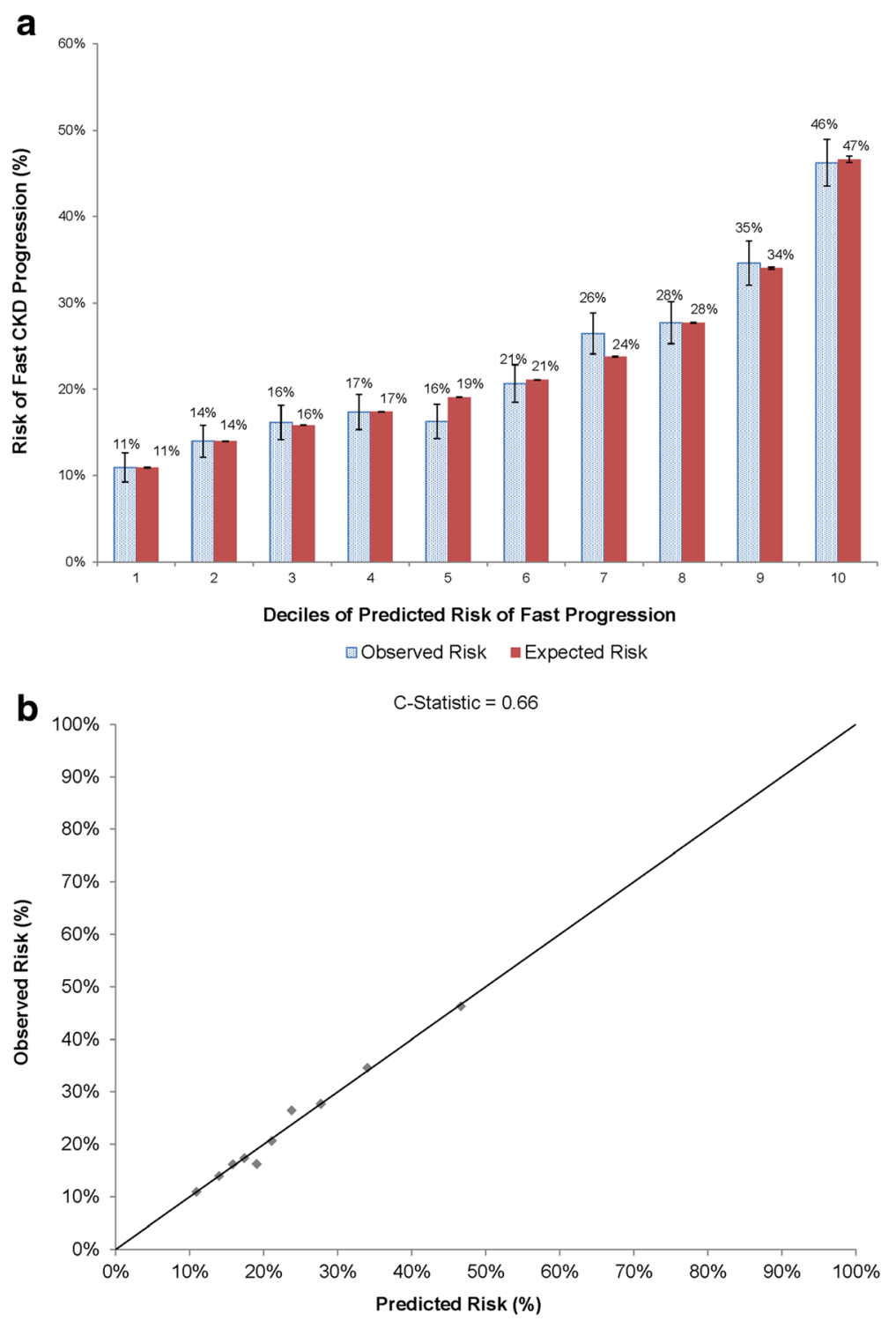

Fig. 3 Accuracy of predictive model for fast CKD progression over 2 years in patients with eGFR 30 to $59 \mathrm{ml} / \mathrm{min} / 1.73 \mathrm{~m}^{2}$ and diabetes mellitus at entry, based on (a) comparison of observed vs. predicted risks within deciles of predicted risk and (b) model calibration across the spectrum of observed risk

of Atherosclerosis (MESA), having a systolic blood pressure $\geq 130 \mathrm{mmHg}$ was associated with a more than twofold higher adjusted odds (odds ratio 2.29, 95\% CI:1.20-4.37) of CKD progression, defined as $>2.5 \mathrm{ml} / \mathrm{min} / 1.73 \mathrm{~m}^{2}$ decline in eGFR over 5 years of follow-up when estimating GFR using combined serum creatinine and cystatin C data [39]. Our study supports and extends these findings in a much larger cohort showing a graded increased risk of fast CKD progression with systolic blood pressure $>120 \mathrm{mmHg}$ even after additional adjustment for receipt of different antihypertensive agents.

Lower hemoglobin levels below $13.0 \mathrm{~g} / \mathrm{dL}$ were also associated with a higher risk of fast progression. These results are consistent with an analysis of 6100 adults with systolic heart failure showing that a hematocrit $<36 \%$ (hemoglobin of approximately $<12.0 \mathrm{~g} / \mathrm{dL}$ ) was associated with a higher adjusted odds (odds ratio 1.30, 95\% CI:1.181.45) of rapid decline in kidney function (defined as $\geq 6 \mathrm{ml} / \mathrm{min} / 1.73 \mathrm{~m}^{2}$ decrease in eGFR per year) and was more prominent in those with CKD (adjusted odds ratio 1.71, 95\% CI:1.43-2.05) [20]. In addition, hemoglobin levels were lower among 117 Stage 3 CKD patients who progressed (eGFR decline $>3 \mathrm{ml} / \mathrm{min} / 1.73 \mathrm{~m}^{2}$ per year over 4 years) compared with 364 Stage 3 CKD patients considered non-progressors $\left(<1 \mathrm{ml} / \mathrm{min} / 1.73 \mathrm{~m}^{2}\right.$ per year over 4 years) [40]. 
There have been conflicting data about the association between different lipoproteins and the risks of ESRD or significant loss of kidney function in adults with CKD. For example, in the Chronic Renal Insufficiency Cohort (CRIC) Study, none of the lipoproteins studied (total, LDL, HDL, VLDL, Lp(a), apoA-I, apoB) were independently associated with development of ESRD or $>50 \%$ reduction in baseline eGFR [41]. In contrast, among a Japanese population with CKD [42], the highest two quartiles of triglyceride-to-HDL cholesterol ratio were associated with rapid decline (defined as $>5 \mathrm{ml} / \mathrm{min} / 1.73 \mathrm{~m}^{2}$ reduction per year) compared with the lowest quartile, which supports our observation that a lower HDL level was associated with a graded, increased risk of fast CKD progression in the subset of patients without diabetes.

Despite evaluating a wide range of candidate predictors of fast progression of CKD, our model discrimination was moderate for models in patients with (c statistic 0.66 ) or without (c statistic 0.64) diabetes which is in contrast to models of initiation of renal replacement therapy which achieve much higher c statistics (0.84-0.90) [5, 8], depending on the severity of the CKD population studied and time horizon used. This highlights the challenge of accurately discriminating which subset of patients starting at an eGFR 30 to $59 \mathrm{ml} / \mathrm{min} / 1.73 \mathrm{~m}^{2}$ will experience fast progression of CKD and the need for investigation of additional factors influencing this risk to potentially intervene earlier in the process to delay the progression to ESRD. Importantly, however, model calibration (i.e., the ability to correctly estimate absolute risk of fast CKD progression over 2 years) was outstanding in patients with and without diabetes at entry, which highlights the potential clinical value in providing prognostic information to patients with stage 3 CKD (Figs. 2 and 3 ).

The study was strengthened by inclusion of a large, racially/ethnically diverse sample of adults with mild-to-moderate CKD who had approximately annual outpatient, non-emergency department measurements of serum creatinine from baseline through the first 2 years of follow-up. This allowed us to examine annual rate of eGFR decline and to identify the subgroup of patients who experienced fast CKD progression. All relevant diagnoses, procedures, test results and treatments were comprehensively captured through a state-of-the-art electronic medical record system that facilitated assessment of relevant patient characteristics which may predict fast CKD progression. Our study also had some limitations. For each patient, we calculated an average annual rate of eGFR decline estimated using linear regression, but patients may experience non-linear patterns of change in kidney function not reflected using this approach. Since this was a retrospective study of patients receiving clinically obtained measures of eGFR (rather than a structured research protocol with annual assessment of kidney function), the findings may not apply to all patients with eGFR $30-59 \mathrm{ml} / \mathrm{min} / 1.73 \mathrm{~m}^{2}$. We also used estimated GFR rather than measured GFR which may lead to some misclassification [43]. Similarly, results may not be completely generalizable to other clinical practice settings or to uninsured patients who may experience a different intensity of treatment or follow-up. Even though we examined a wide range of patient characteristics, we cannot rule out residual confounding affecting our model results. We were unable to comprehensively identify exposure to nephrotoxic insults or episodes of acute kidney injury from available data. Systematic information on other selected biomarkers that have been associated with different measures of CKD progression were also not available (e.g., urinary phosphorus excretion [44], serum calcium and phosphorus [40], serum bicarbonate [40, 45], NT-proBNP [19], or troponin T [19]).

\section{Conclusions}

In sum, within a large, contemporary population of adults with mild-to-moderate CKD, accelerated progression of kidney dysfunction within 2 years affected $\sim 1$ in 4 patients with diabetes and $\sim 1$ in 7 without diabetes. Regardless of diabetes status, the independent predictors of fast CKD progression included proteinuria, elevated systolic blood pressure, heart failure, anemia, and age $\geq$ 80 years. Age 18-49 years was also a predictor in those with diabetes, while additional predictors in patients without diabetes included smoking history, prior ischemic stroke, prior pacemaker implantation, and HDL cholesterol $<60 \mathrm{mg} / \mathrm{dL}$. These findings may help in identifying the subset of patients who may benefit from more frequent monitoring of eGFR to identify fast CKD progression or proteinuria and subsequent intervention to potentially retard further loss of kidney function and other potentially associated adverse clinical outcomes such as cardiovascular events.

\section{Abbreviations \\ CKD: Chronic kidney disease; eGFR: Estimated glomerular filtration rate; ESRD: End-stage renal disease; KPNC: Kaiser Permanente Northern California}

\section{Acknowledgements}

The authors would like to thank Susan S. Kim for her technical assistance.

\section{Funding}

This study was supported by a research grant through Dr. Go's institution from AstraZeneca.

\section{Availability of data and materials}

The datasets generated and/or analyzed during the current study are not publicly available due to the data extracted from systems belonging to Kaiser Permanente Northern California.

\section{Authors' contributions}

ASG, JRY, TCT and JDO designed the study. ASG and JRY were responsible for assembling and analyzing the dataset and take responsibility for the accuracy of the findings. ASG, JRY and TCT drafted the manuscript. All authors read, provided critical revisions to and approved the final manuscript. 


\section{Ethics approval and consent to participate}

This study was approved by the Kaiser Permanente Northern California institutional review board. A waiver of consent was obtained due to the nature of the study.

\section{Consent for publication}

Not applicable.

\section{Competing interests}

Drs. Cabrera, Stefansson and Greasley are employees of Astra-Zeneca. Ms. Yang, Ms. Tan and Dr. Ordonez declare that they have no competing interests.

\section{Publisher's Note}

Springer Nature remains neutral with regard to jurisdictional claims in published maps and institutional affiliations.

\section{Author details}

${ }^{1}$ Division of Research, Kaiser Permanente Northern California, 2000 Broadway, Oakland, CA, USA. ${ }^{2}$ Departments of Epidemiology, Biostatistics and Medicine, University of California, San Francisco, San Francisco, CA, USA. ${ }^{3}$ Department of Health Research and Policy, Stanford University School of Medicine, Palo Alto, CA, USA. ${ }^{4}$ Astra-Zeneca, Gothenburg, Sweden. ${ }^{5}$ Division of Nephrology, Kaiser Permanente Oakland Medical Center, Oakland, CA, USA.

\section{Received: 18 September 2017 Accepted: 7 June 2018}

Published online: 22 June 2018

\section{References}

1. Griesdale D, Ishikawa S, Lohser J. About predictors of acute kidney injury after lung resection. Reply. Anesth Analg. 2013;116(2):505-6.

2. Bruck K, Stel VS, Gambaro G, Hallan S, Volzke H, Arnlov J, Kastarinen M, Guessous I, Vinhas J, Stengel B, et al. CKD prevalence varies across the European general population. J Am Soc Nephrol. 2016;27(7):2135-47.

3. Go AS, Chertow GM, Fan D, McCulloch CE, Hsu CY. Chronic kidney disease and the risks of death, cardiovascular events, and hospitalization. N Engl J Med. 2004;351(13):1296-305.

4. Turin TC, Tonelli M, Manns BJ, Ahmed SB, Ravani P, James M, Hemmelgarn BR. Lifetime risk of ESRD. J Am Soc Nephrol. 2012;23(9):1569-78.

5. Tangri N, Stevens LA, Griffith J, Tighiouart H, Djurdjev O, Naimark D, Levin A, Levey AS. A predictive model for progression of chronic kidney disease to kidney failure. Jama. 2011;305(15):1553-9.

6. Echouffo-Tcheugui JB, Kengne AP. Risk models to predict chronic kidney disease and its progression: a systematic review. PLoS Med. 2012;9(11): e1001344.

7. Johnson ES, Thorp ML, Platt RW, Smith DH. Predicting the risk of dialysis and transplant among patients with CKD: a retrospective cohort study. Am J Kidney Dis. 2008;52(4):653-60

8. Tangri N, Grams ME, Levey AS, Coresh J, Appel LJ, Astor BC, Chodick G, Collins AJ, Djurdjev O, Elley CR, et al. Multinational assessment of accuracy of equations for predicting risk of kidney failure: a meta-analysis. Jama. 2016; 315(2):164-74

9. US Renal Data System: Annual Data Report. 2014. http://www.usrds.org/adr. aspx. Accessed 22 Dec 2015

10. Kovesdy CP, Coresh J, Ballew SH, Woodward M, Levin A, Naimark DM, Nally J, Rothenbacher D, Stengel B, Iseki K, et al. Past decline versus current eGFR and subsequent ESRD risk. J Am Soc Nephrol. 2016;27(8):2447-55.

11. Naimark DM, Grams ME, Matsushita K, Black C, Drion I, Fox CS, Inker LA, Ishani A, Jee SH, Kitamura A, et al. Past decline versus current eGFR and subsequent mortality risk. J Am Soc Nephrol. 2016;27(8):2456-66.

12. Lambers Heerspink HJ, Tighiouart H, Sang Y, Ballew S, Mondal H, Matsushita K, Coresh J, Levey AS, Inker LA. GFR decline and subsequent risk of established kidney outcomes: a meta-analysis of 37 randomized controlled trials. Am J Kidney Dis. 2014;64(6):860-6

13. Coresh J, Turin TC, Matsushita K, Sang Y, Ballew SH, Appel U, Arima H, Chadban SJ, Cirillo M, Djurdjev O, et al. Decline in estimated glomerular filtration rate and subsequent risk of end-stage renal disease and mortality. JAMA. 2014;311(24):2518-31.

14. Rahman M, Xie D, Feldman HI, Go AS, He J, Kusek JW, Lash J, Miller ER 3rd, Ojo A, Pan Q, et al. Association between chronic kidney disease progression and cardiovascular disease: results from the CRIC study. Am J Nephrol. 2014; 40(5):399-407.
15. Merrill RM, Kessler LG, Udler JM, Rasband GC, Feuer EJ. Comparison of risk estimates for selected diseases and causes of death. Prev Med. 1999;28(2):179-93.

16. Krop JS, Coresh J, Chambless LE, Shahar E, Watson RL, Szklo M, Brancati FL. A community-based study of explanatory factors for the excess risk for early renal function decline in blacks vs whites with diabetes: the atherosclerosis risk in communities study. Arch Intern Med. 1999;159(15):1777-83.

17. Sukmark T, Sukmark S. Predictors of faster progression in chronic kidney disease. J Med Assoc Thail. 2014;97(8):812-9.

18. Rucci P, Mandreoli M, Gibertoni D, Zuccala A, Fantini MP, Lenzi J, Santoro A. A clinical stratification tool for chronic kidney disease progression rate based on classification tree analysis. Nephrol Dial Transplant. 2014;29(3):603-10.

19. Bansal N, Katz R, Dalrymple L, de Boer I, DeFilippi C, Kestenbaum B, Park M, Sarnak M, Seliger S, Shlipak M. NT-proBNP and troponin T and risk of rapid kidney function decline and incident CKD in elderly adults. Clin J Am Soc Nephrol. 2015:10(2):205-14.

20. Bansal N, Tighiouart H, Weiner D, Griffith J, Vlagopoulos P, Salem D, Levin A, Sarnak MJ. Anemia as a risk factor for kidney function decline in individuals with heart failure. Am J Cardiol. 2007;99(8):1137-42.

21. Gordon NP. Characteristics of Adult Health Plan Members in the Northern California Region Membership, as Estimated from the 2011 Member Health Survey. Oakland: Division of Research, Kaiser Permanente Medical Care Program; 2013.

22. Levey AS, Stevens LA, Schmid CH, Zhang YL, Castro AF 3rd, Feldman HI, Kusek JW, Eggers P, Van Lente F, Greene T, et al. A new equation to estimate glomerular filtration rate. Ann Intern Med. 2009;150(9):604-12.

23. Curb JD, Ford CE, Pressel S, Palmer M, Babcock C, Hawkins CM. Ascertainment of vital status through the National Death Index and the Social Security Administration. Am J Epidemiol. 1985;121(5):754-66.

24. Arellano MG, Petersen GR, Petitti DB, Smith RE. The California Automated Mortality Linkage System (CAMLIS). Am J Public Health. 1984;74(12):1324-30.

25. Rifkin DE, Shlipak MG, Katz R, Fried LF, Siscovick D, Chonchol M, Newman $A B$, Sarnak MJ. Rapid kidney function decline and mortality risk in older adults. Arch Intern Med. 2008;168(20):2212-8.

26. Smith DH, Thorp ML, Gurwitz JH, McManus DD, Goldberg RJ, Allen LA, Hsu G, Sung SH, Magid DJ, Go AS. Chronic kidney disease and outcomes in heart failure with preserved versus reduced ejection fraction: the cardiovascular research network PRESERVE study. Circ Cardiovasc Qual Outcomes. 2013;6(3):333-42.

27. Go AS, Lee WY, Yang J, Lo JC, Gurwitz JH. Statin therapy and risks for death and hospitalization in chronic heart failure. Jama. 2006;296(17):2105-11.

28. Austin PC. Using the standardized difference to compare the prevalence of a binary variable between two groups in observational research. Commun Stat Simul Comput. 2009;38:1228-34.

29. Austin PC. An introduction to propensity score methods for reducing the effects of confounding in observational studies. Multivar Behav Res. 2011; 46(3):399-424.

30. Alba AC, Agoritsas T, Walsh M, Hanna S, lorio A, Devereaux PJ, McGinn T, Guyatt G. Discrimination and calibration of clinical prediction models: users' guides to the medical literature. JAMA. 2017;318(14):1377-84

31. Li L, Astor BC, Lewis J, Hu B, Appel LJ, Lipkowitz MS, Toto RD, Wang X, Wright JT Jr, Greene TH. Longitudinal progression trajectory of GFR among patients with CKD. Am J Kidney Dis. 2012:59(4):504-12.

32. Marks A, Fluck N, Prescott GJ, Robertson LM, Simpson WG, Smith WC, Black C. Definitions of progression in chronic kidney disease-predictors and relationship to renal replacement therapy in a population cohort with a 6 year follow-up. Nephrol Dial Transplant. 2014;29(2):333-41.

33. Bleyer AJ, Shemanski LR, Burke GL, Hansen KJ, Appel RG. Tobacco, hypertension, and vascular disease: risk factors for renal functional decline in an older population. Kidney Int. 2000;57(5):2072-9.

34. Baggio B, Budakovic A, Perissinotto E, Maggi S, Cantaro S, Enzi G, Grigoletto F. Atherosclerotic risk factors and renal function in the elderly: the role of hyperfibrinogenaemia and smoking. Results from the talian Longitudinal Study on Ageing (ILSA). Nephrol Dial Transplant. 2005;20(1):114-23

35. Hsu CY, Iribarren C, McCulloch CE, Darbinian J, Go AS. Risk factors for endstage renal disease: 25-year follow-up. Arch Intern Med. 2009;169(4):342-50.

36. Klag MJ, Whelton PK, Randall BL, Neaton JD, Brancati FL, Ford CE, Shulman NB, Stamler J. Blood pressure and end-stage renal disease in men. N Engl J Med. 1996:334(1):13-8.

37. Hsu CY, McCulloch CE, Darbinian J, Go AS, Iribarren C. Elevated blood pressure and risk of end-stage renal disease in subjects without baseline kidney disease. Arch Intern Med. 2005;165(8):923-8. 
38. Anderson AH, Yang W, Townsend RR, Pan Q, Chertow GM, Kusek JW, Charleston J, He J, Kallem R, Lash JP, et al. Time-updated systolic blood pressure and the progression of chronic kidney disease: a cohort study. Ann Intern Med. 2015;162(4):258-65.

39. Bloomfield GS, Yi SS, Astor BC, Kramer H, Shea S, Shlipak MG, Post WS. Blood pressure and chronic kidney disease progression in a multi-racial cohort: the multi-ethnic study of atherosclerosis. J Hum Hypertens. 2013; 27(7):421-6.

40. Chase HS, Hirsch JS, Mohan S, Rao MK, Radhakrishnan J. Presence of early CKD-related metabolic complications predict progression of stage 3 CKD: a case-controlled study. BMC Nephrol. 2014;15:187.

41. Rahman M, Yang W, Akkina S, Alper A, Anderson AH, Appel $\sqcup$, He J, Raj DS, Schelling J, Strauss $L$, et al. Relation of serum lipids and lipoproteins with progression of CKD: the CRIC study. Clin J Am Soc Nephrol. 2014;9(7):1190-8.

42. Tsuruya K, Yoshida H, Nagata M, Kitazono T, Iseki K, Iseki C, Fujimoto S, Konta T, Moriyama T, Yamagata K, et al. Impact of the triglycerides to high-density lipoprotein cholesterol ratio on the incidence and progression of CKD: a longitudinal study in a large Japanese population. Am J Kidney Dis. 2015;66(6):972-83.

43. Ramspek CL, Nacak H, van Diepen M, van Buren M, Krediet RT, Rotmans Jl, Dekker FW, Group NS. Pre-dialysis decline of measured glomerular filtration rate but not serum creatinine-based estimated glomerular filtration rate is a risk factor for mortality on dialysis. Nephrol Dial Transplant. 2017;32(1):89-96.

44. Kawasaki T, Maeda Y, Matsuki H, Matsumoto Y, Akazawa M, Kuyama T. Urinary phosphorus excretion per creatinine clearance as a prognostic marker for progression of chronic kidney disease: a retrospective cohort study. BMC Nephrol. 2015;16:116.

45. Dobre M, Yang W, Chen J, Drawz P, Hamm LL, Horwitz E, Hostetter T, Jaar B, Lora CM, Nessel L, et al. Association of serum bicarbonate with risk of renal and cardiovascular outcomes in CKD: a report from the Chronic Renal Insufficiency Cohort (CRIC) study. Am J Kidney Dis. 2013;62(4):670-8.

Ready to submit your research? Choose BMC and benefit from:

- fast, convenient online submission

- thorough peer review by experienced researchers in your field

- rapid publication on acceptance

- support for research data, including large and complex data types

- gold Open Access which fosters wider collaboration and increased citations

- maximum visibility for your research: over $100 \mathrm{M}$ website views per year

At BMC, research is always in progress.

Learn more biomedcentral.com/submissions 